\title{
Subintimal Angioplasty for Peripheral Arterial Occlusive Disease: A Systematic Review
}

\author{
Rosemarie Met · Krijn P. Van Lienden · Mark J. W. Koelemay • \\ Shandra Bipat $\cdot$ Dink A. Legemate $\cdot$ Jim A. Reekers
}

Received: 29 January 2008/Accepted: 28 February 2008/Published online: 15 April 2008

(C) The Author(s) 2008

\begin{abstract}
The objective of this study was to summarize outcomes of subintimal angioplasty (SA) for peripheral arterial occlusive disease. The Cochrane Library, Medline and Embase databases were searched to perform a systematic review of the literature from 1966 through May 2007 on outcomes of SA for peripheral arterial occlusive disease of the infrainguinal vessels. The keywords "percutaneous intentional extraluminal revascularization," "subintimal angioplasty," "peripheral arterial disease," "femoral artery," "popliteal artery," and "tibial artery" were used. Assessment of study quality was done using a form based on a checklist of the Dutch Cochrane Centre. The recorded outcomes were technical and clinical success, primary
\end{abstract}

R. Met · K. P. Van Lienden · S. Bipat · J. A. Reekers Department of Radiology, Academic Medical Center, Meibergdreef 9, 1105 AZ Amsterdam, The Netherlands

R. Met

e-mail: r.met@amc.nl

K. P. Van Lienden

e-mail: k.p.vanlienden@amc.nl

S. Bipat

e-mail: s.bipat@amc.nl

M. J. W. Koelemay · D. A. Legemate

Department of Vascular Surgery, Academic Medical Center, Meibergdreef 9, 1105 AZ Amsterdam, The Netherlands

e-mail: m.j.koelemaij@amc.nl

D. A. Legemate

e-mail: d.a.legemate@amc.nl

J. A. Reekers $(\bowtie)$

Department of Radiology, Academic Medical Center, P.O. Box

22660, 1100 DD Amsterdam, The Netherlands

e-mail: j.a.reekers@amc.uva.nl (assisted) patency, limb salvage, complications, and survival, in relation to the clinical grade of disease (intermittent claudication or critical limb ischemia [CLI] or mixed) and location of lesion (femoropopliteal, crural, or mixed). Twenty-three cohort studies including a total of 1549 patients (range, 27 to 148) were included in this review. Methodological and reporting quality were moderate, e.g., there was selection bias and reporting was not done according to the reporting standards. These and significant clinical heterogeneity obstructed a meta-analysis. Reports about length of the lesion and TASC classification were too various to summarize or were not mentioned at all. The technical success rates varied between $80 \%$ and $90 \%$, with lower rates for crural lesions compared with femoral lesions. Complication rates ranged between $8 \%$ and $17 \%$ and most complications were minor. After 1 year, clinical success was between $50 \%$ and $70 \%$, primary patency was around $50 \%$ and limb salvage varied from $80 \%$ to $90 \%$. In conclusion, taking into account the methodological shortcomings of the included studies, SA can play an important role in the treatment of peripheral arterial disease, especially in the case of critical limb ischemia. Despite the moderate patency rates after one year, SA may serve as a "temporary bypass" to provide wound healing and limb salvage.

Keywords Subintimal angioplasty .

Peripheral arterial disease - Revascularization ·

Percutaneous intentional extraluminal recanalization .

Systematic review

\section{Introduction}

Since it was first described in 1990 [1], subintimal angioplasty (SA) has become an established percutaneous 
technique to overcome long and chronic arterial occlusions. It is also known as percutaneous intentional extraluminal recanalization (PIER) [2]. Initially it was used only for femoral and popliteal occlusions, but now it is also applied to long crural artery occlusions [3]. This therapy, being minimally invasive, offers many advantages compared with other treatment options. Patients need only local anesthesia to enable access to the common femoral artery, and after the procedure they are quickly ambulatory again. In addition, failed SA does not preclude the opportunity for surgical revascularization [4]. Despite these advantages, there are also specialists who adopt a critical attitude toward SA. They state that it is difficult to learn, that the long-term results are not known, and that there are no randomized studies comparing SA with surgery. To determine the clinical value of this technique, a systematic review of available evidence is needed. The aim of this study was to systematically review the literature on the technical and clinical outcomes of subintimal angioplasty for peripheral arterial occlusive disease.

\section{Methods}

\section{Literature Search}

A systematic search of literature was performed with assistance of a clinical librarian in the medical databases National Guideline Clearinghouse, Trip database, Bandolier, British Medical Journal Clinical Evidence, Medline (January 1966 through May 2007), Embase (January 1980 through May 2007), and Cochrane Library, comprising the Database of Systematic Reviews (1988 through May 2007). The keywords "percutaneous intentional extraluminal revascularization," "subintimal angioplasty," "peripheral arterial disease," "femoral artery," "popliteal artery," and "tibial artery" were used, along with synonyms of them. There was no language restriction. Titles and abstracts were screened by two reviewers (R.M. and K.P.L.) independently to identify potentially relevant articles, using the inclusion and exclusion criterion. Discrepancies in judgment were resolved after discussion and, when necessary, after mediation of a third reviewer (S.B.). Full text of these articles was retrieved for further analysis.

\section{Criteria for Inclusion}

The same two reviewers (R.M. and K.P.L.) independently checked the retrieved articles on inclusion criteria using a standardized form. Clinical studies were selected when all of the inclusion criteria were met. First, patients had to be treated for a femoral, popliteal, or crural occlusion by SA (studies reporting a maximum of 5\% iliac occlusions were also included). Second, at least one of the following outcome parameters of interest-i.e., technical success, primary patency after 1 year, and limb salvage after 1 year-had to be reported. Technical success was defined as good antegrade flow at completion of the procedure. Primary patency after 1 year must be measured by an established imaging technique, i.e., duplex scanning, computed tomography angiography (CTA), magnetic resonance angiography (MRA), or digital subtraction angiography (DSA). Third, the study should include a minimum of 10 patients. Fourth, it should be an original patient series (studies containing duplicate material were excluded and the ones with the best documented material were included for analysis).

\section{Study Quality}

Studies fulfilling all inclusion criteria were checked on study quality characteristics by two reviewers (R.M. and K.P.L.) independently. Assessment of study quality was done using a form based on a checklist of the Dutch Cochrane Centre [5]. The main points of appraisal included description of (1) patient selection, (2) patient characteristics, (3) location of lesion, (4) technique, (5) follow-up, (6) assessment of patency, and (7) definition of outcome. Each item was described clearly, described moderate to badly, or not described at all. Articles were considered to be valid and selected for data extraction if items $2,3,4$, and 7 were described clearly. An article could be included, despite incomplete or very short follow-up, because one important outcome, i.e., technical success, is independent of follow-up.

\section{Data Extraction}

The following data were recorded per study: method of data collection (prospective or retrospective), selection of patients for the intervention (indication for SA), and selection of patients for the study (consecutive or selected and, if selected, inclusion and exclusion criteria). Furthermore, patient characteristics (number of patients, sex, age, indication [claudication, rest pain, gangrene], and most important risk factors, i.e., diabetes, smoking, hypertension, renal failure) and characteristics of treated lesions (location, length, outflow) were recorded. Finally, data about the procedure were collected such as technique (materials, stent placement, anticoagulants during procedure), performer (number of different interventional radiologists, experience), use of anticoagulants after the procedure, and follow-up data.

The following outcomes were recorded and analyzed: technical and clinical success, primary (assisted) patency, 
limb salvage, complications, and survival. Data extraction was done by two reviewers (R.M. and K.P.L.) independently. Discrepancies in evaluation were resolved after discussion and, when necessary, after mediation of a third reviewer (S.B.).

\section{Data Analysis}

The studies were subdivided into different groups according to the clinical grade of disease (intermittent claudication [IC] or critical limb ischemia [CLI] or mixed) and location of lesion (femoral-popliteal, crural, or mixed). Studies that included mainly patients with CLI and $<15 \%$ patients with IC were analyzed in the CLI group, and vice versa. A mixed patient population was defined as a patient group consisting of both $>15 \%$ claudicants as well as $>15 \%$ CLI patients. We intended to perform a metaanalysis if data were clinically homogeneous by calculating summary estimates with nonlinear models using either random-effects or fixed-effects approaches.

Many studies reported patency and limb salvage only for cases which were technically successful. For this systematic review we considered technically unsuccessful cases as not patent and calculated patency rates and limb salvage rates for the total group of treated patients, including technically unsuccessful cases.

Reporting was according to the consensus statement of the Meta-analysis Of Observational Studies in Epidemiology (MOOSE) group [6].

\section{Results}

\section{Search Strategy and Study Selection}

The initial search yielded 151 articles (Fig. 1). After screening of title and abstract, 105 articles were excluded. The most frequent reasons for exclusion were study design

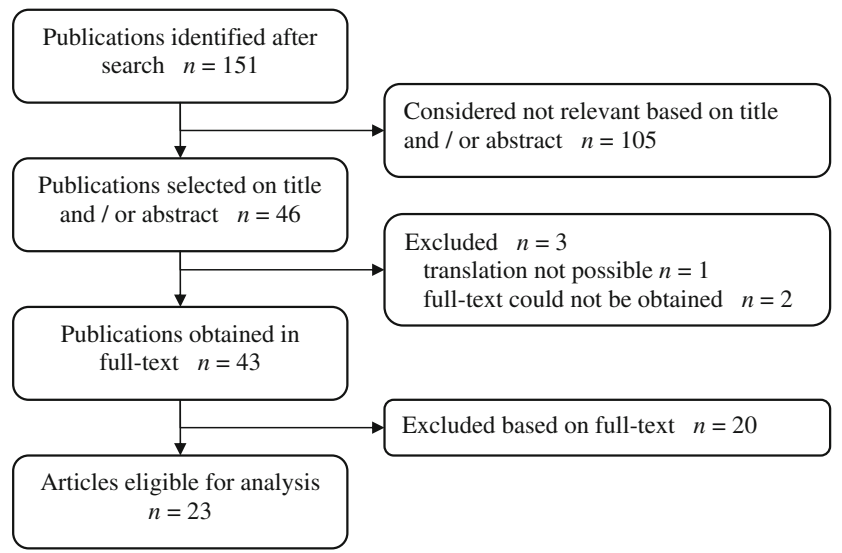

Fig. 1 Flowchart showing selection of papers for analysis (review, case report), technique (other than SA), and location of lesion (iliac artery or extending from the femoral into the iliac artery). For the remaining 46 papers, two full copies [7, 8] could not be obtained, and translation of one Lithuanian article [9] was not possible. After assessment of 43 full text publications, 20 articles were excluded, mainly because of inadequate description of patient or lesion characteristics or use of another (sometimes experimental) endovascular technique.

Finally, 23 articles [2, 10-31] were included in this review. We did not find randomized controlled trials. Most of the studies were retrospective $(n=11)$ or prospective $(n=8)$ patient series. In four studies, it remained unclear whether data collection was pro- or retrospective $[13,15$, $19,29]$. Quality assessment of the studies is shown in Table 1.

\section{Study Characteristics}

Characteristics of all included studies are shown in Tables 2, 3, 4. The authors often described that they included consecutive patients undergoing SA, but the selection procedure for the treatment remained unclear. If it was described, there was a large variation in patient selection. Two studies $[13,28]$ included patients in whom amputation was inevitable without treatment; two other studies [17, 18] selected every patient presenting with critical limb ischemia; five studies [11, 19, 21, 26, 29] included patients who met one of the following conditions: (a) lack of vein suitable for surgical reconstruction, (b) poor medical condition, (c) unfavorable anatomy for bypass grafting, and (d) favorable anatomy for SA. One study [31] selected only patients who refused surgery or in whom surgery was contraindicated. The studies varied in size from 27 to 148 patients. Studies reported age in different ways: some gave median age; others, mean age. The ages were between 59 and 81 years; most studies (16/23) reported ages (some mean and others median) between 70 and 80 years. The percentage of diabetic patients between studies showed a large variation (9\%-72\%). However, the percentage of patients with diabetes was higher in the group of patients treated for CLI (Table 2) compared with the group of patients treated for mixed indications (intermittent claudication or CLI; Table 3). Also, there was a trend that there were more diabetics in the group of patients with mixed disease and mixed lesions compared with patients with mixed disease and a lesion proximal to the knee. Chronic renal failure is not included in the tables because only 9 of 23 articles mentioned it. Use of anticoagulants during the procedure was described in 14 articles; all patients received heparin, with a variation in dose of $50-70 \mathrm{IU} / \mathrm{kg}$ or $2000-5000 \mathrm{IU}$. Some also received nitroglycerin or tolazoline (intra-arterial vasodilating agents to 
Table 1 Quality assessment of all included studies

\begin{tabular}{|c|c|c|c|c|c|c|c|c|c|}
\hline Study & $\begin{array}{l}\text { Year of } \\
\text { publication }\end{array}$ & $\begin{array}{l}\text { Clear } \\
\text { definition } \\
\text { of study } \\
\text { population? }\end{array}$ & $\begin{array}{l}\text { Clear } \\
\text { description } \\
\text { of patient } \\
\text { characteristics? }\end{array}$ & $\begin{array}{l}\text { Clear } \\
\text { description } \\
\text { of lesions? }\end{array}$ & $\begin{array}{l}\text { Clear } \\
\text { description } \\
\text { of } \\
\text { technique? }\end{array}$ & $\begin{array}{l}\text { Follow-up } \\
\text { complete? }\end{array}$ & $\begin{array}{l}\text { Objective } \\
\text { assessment } \\
\text { of patency? }\end{array}$ & $\begin{array}{l}>\text { Clear } \\
\text { definition } \\
\text { of } \\
\text { outcomes? }\end{array}$ & $\operatorname{Sum}^{\mathrm{a}}$ \\
\hline London [20] & 1994 & + & + & + & + & - & $+/-$ & + & 11 \\
\hline Reekers [2] & 1994 & + & + & + & + & $+1-$ & $+/-$ & $+/-$ & 11 \\
\hline Nydahl [23] & 1997 & + & + & + & + & + & + & + & 14 \\
\hline McCarthy [21] & 2000 & + & + & + & - & $+/-$ & + & + & 11 \\
\hline Vraux \& Hammer [29] & 2000 & + & + & + & + & $+/-$ & + & + & 13 \\
\hline Ingle [14] & 2002 & + & + & + & + & + & - & $+/-$ & 11 \\
\hline Shaw [24] & 2002 & + & + & + & - & + & + & + & 12 \\
\hline Tisi [27] & 2002 & + & + & + & $+/-$ & + & $?$ & + & 11 \\
\hline Laxdal [16] & 2003 & + & + & + & + & - & + & + & 12 \\
\hline Lipsitz [19] & 2003 & + & + & + & + & - & + & $+/-$ & 11 \\
\hline Yilmaz [31] & 2003 & + & + & + & + & - & + & + & 12 \\
\hline Desgranges [11] & 2004 & + & + & + & + & - & + & $+/-$ & 11 \\
\hline Florenes [12] & 2004 & + & + & $+/-$ & + & + & + & - & 11 \\
\hline Hynes [13] & 2004 & + & $+1-$ & + & - & + & + & + & 11 \\
\hline Lazaris \& Tsiamis [17] & 2004 & + & + & + & - & - & $?$ & + & 8 \\
\hline Spinosa [26] & 2004 & + & + & + & + & $+/-$ & $+1-$ & + & 12 \\
\hline Smith [25] & 2005 & + & + & + & + & + & $+/-$ & + & 13 \\
\hline Cho [10] & 2006 & + & + & + & + & - & + & + & 12 \\
\hline Kidd [15] & 2006 & + & + & + & + & + & + & + & 13 \\
\hline Lazaris \& Salas [18] & 2006 & + & + & + & - & - & + & - & 8 \\
\hline Myers [22] & 2006 & + & + & $+/-$ & + & + & + & + & 13 \\
\hline Treiman [28] & 2006 & + & + & + & + & + & + & + & 14 \\
\hline Vraux \& Bertoncello [30] & 2006 & + & + & + & + & $+/-$ & + & + & 13 \\
\hline
\end{tabular}

(+) yes; (-) no; (+/-) moderate; (?) unclear

${ }^{\text {a }}$ Sum of all seven quality indicators: yes $=2$ point, moderate $=1$ point, no or $?=0$ points

minimize vasospasms) during the procedure. Nearly all papers had well-described postprocedural anticoagulant therapy. All patients were given acetylsalicylic acid, sometimes combined with clopidogrel. Only very few papers report the use of additional devices (like stents). The use of re-entry devices is described nowhere. The significant clinical heterogeneity obstructed a meaningful metaanalysis.

\section{Technical Success}

Most studies described technical success as good antegrade flow of the occluded segment at completion of the procedure. Some studies added the condition that there was $<30 \%$ residual stenosis $[11,20,23,25,28,31]$. Technical success percentages (95\% confidence interval) are shown in Figs. 2, 3, and 4. In patients with critical limb ischemia, technical success of crural procedures is lower compared with that for femoral lesions. For patients treated for different disease (CLI or intermittent claudication), technical success rate show a large variation. In general, technical success is between $80 \%$ and $90 \%$.

\section{Clinical Success}

Nine studies reported clinical success, described as resolution or improvement of claudication, relief of pain at rest, healing of ulcers, or healing of minor amputations which were required for gangrene and nonhealing wounds after previous amputation. Clinical success was achieved in $50 \%$ to $70 \%$ of the patients after 1 year (Tables $5,6,7$ ).

\section{Patency}

The definition and reporting of patency varied considerably between studies. Some studies reported primary patency; others primary assisted patency. Primary patency was defined differently among studies as (1) absence of occlusion and absence of $>50 \%$ stenosis in the treated segment; (2) absence of occlusion and absence of $>30 \%$ 


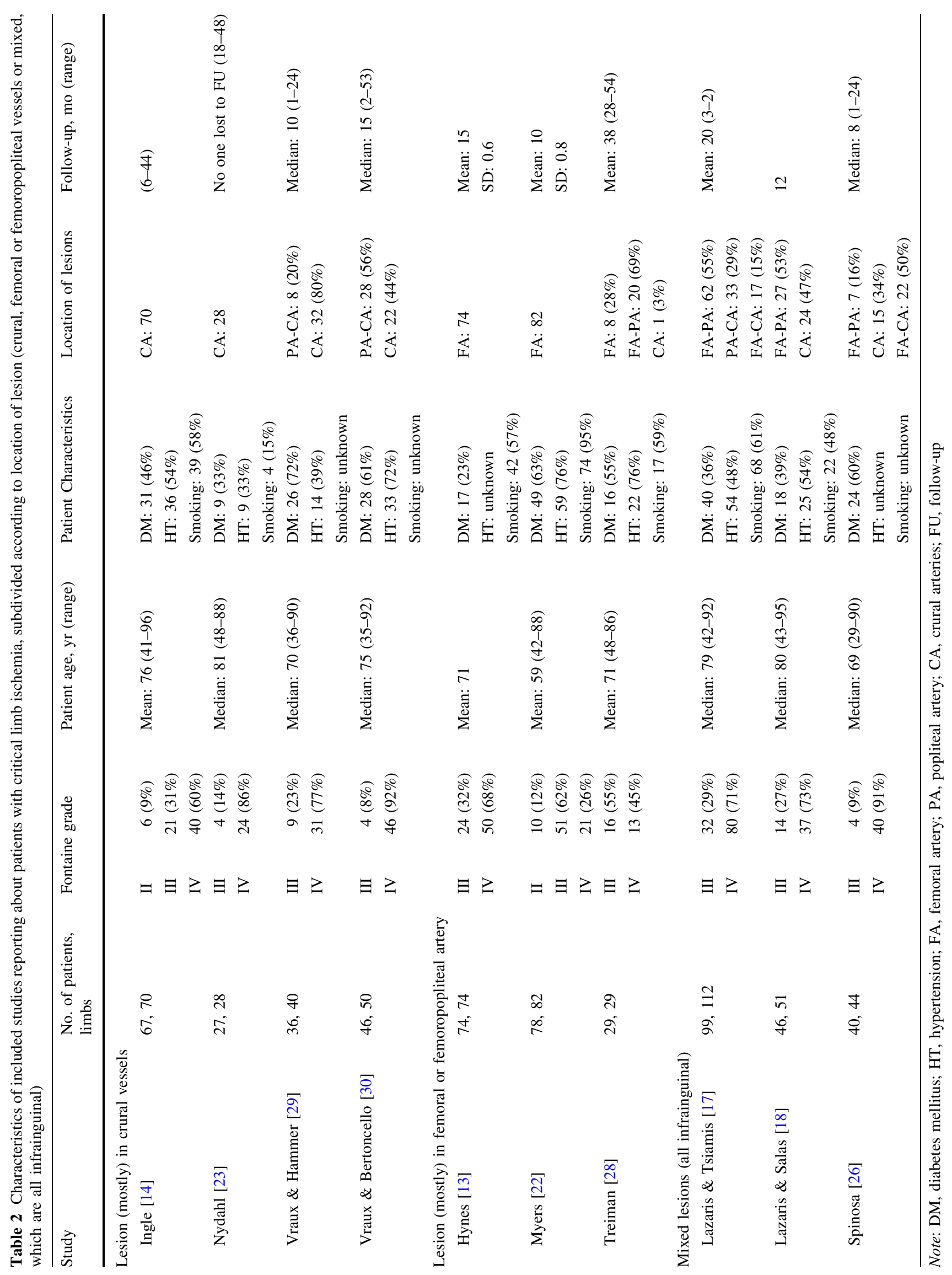




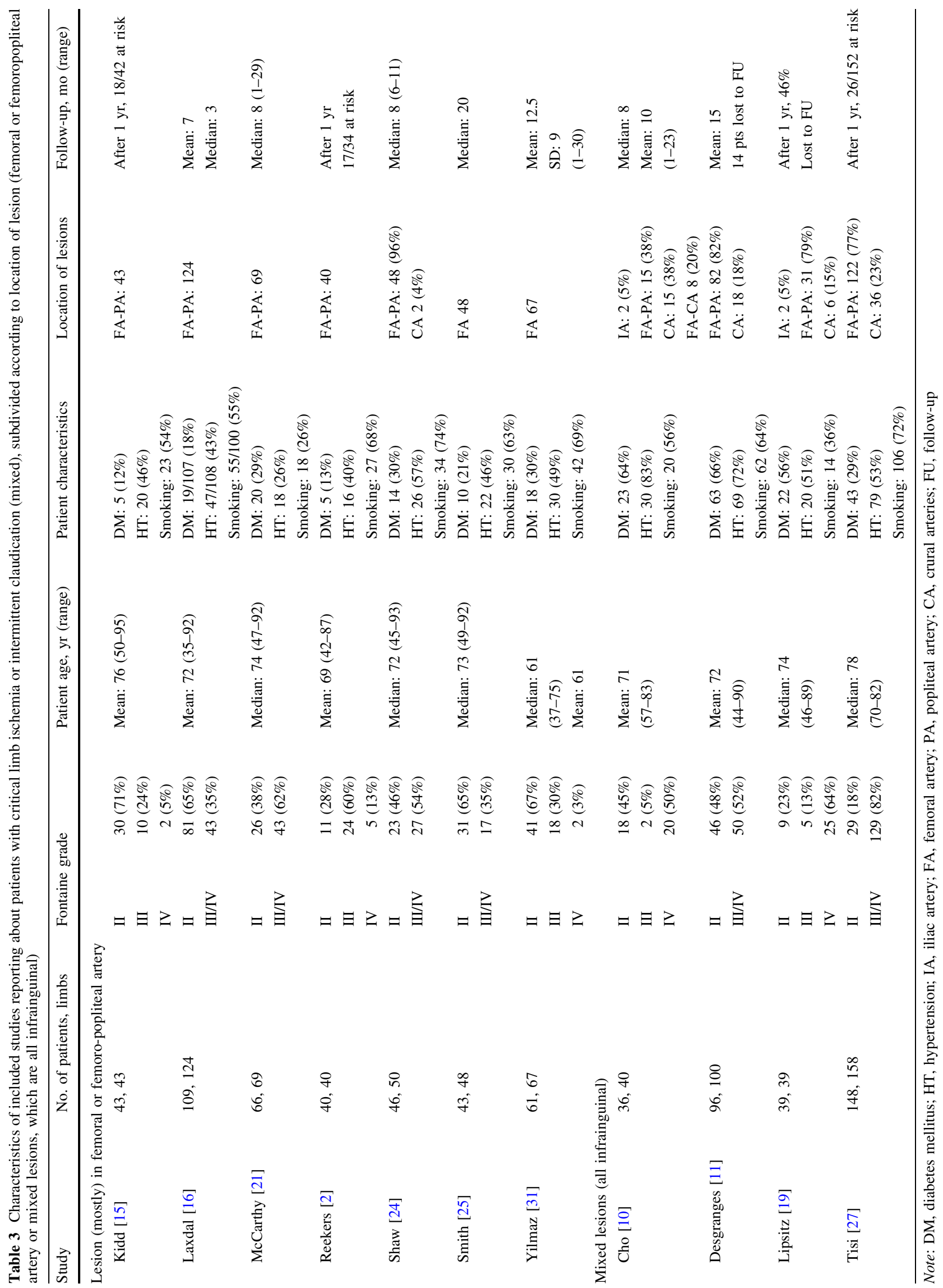


Table 4 Characteristics of included studies reporting about patients with intermittent claudication, subdivided according to location of lesion (femoral or femoropopliteal artery or mixed lesions, which are all infrainguinal)

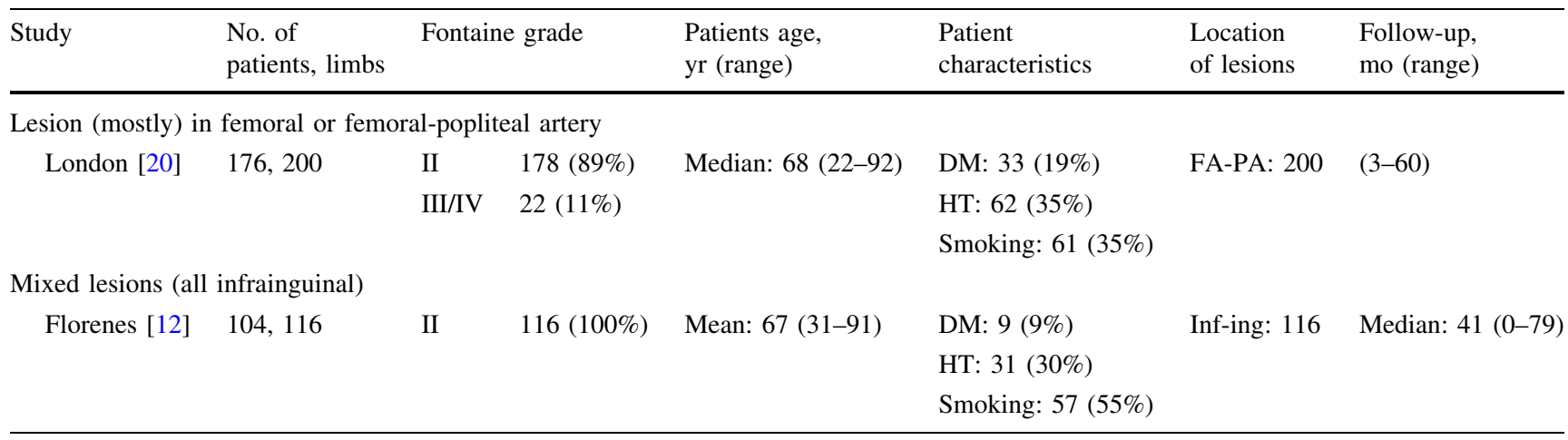

Note: DM, diabetes mellitus; HT, hypertension; FA, femoral artery; PA, popliteal artery; FU, follow-up; Inf-ing, infrainguinal

\section{Critical limb ischemia}

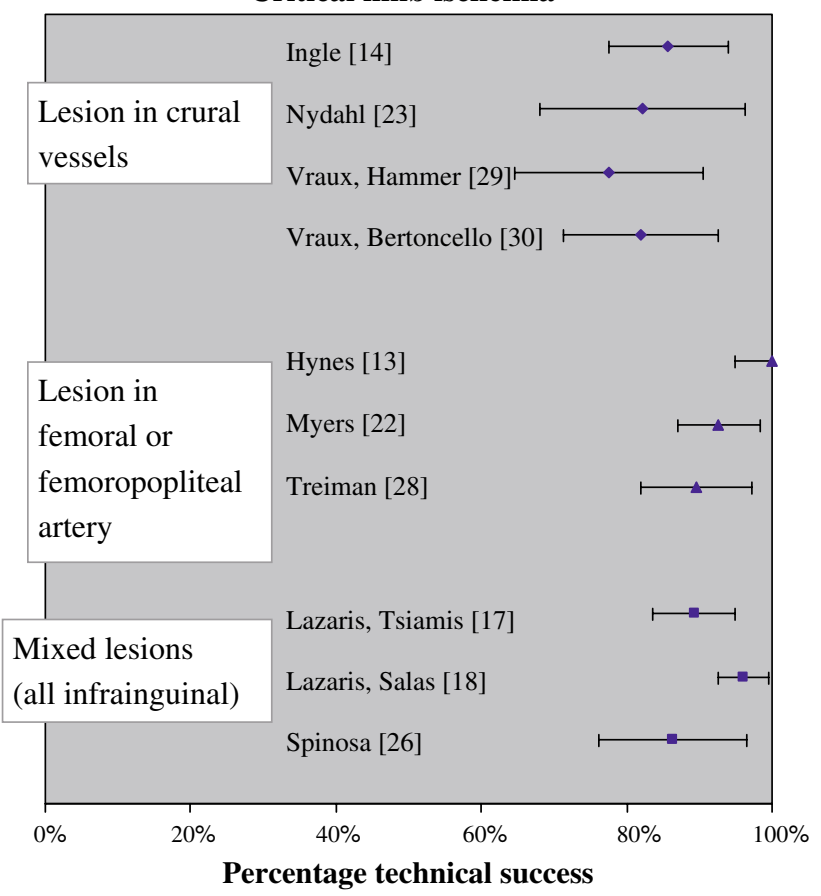

Fig. 2 Technical success accompanied by $95 \%$ confidence interval of all studies reporting patients with critical limb ischemia, subdivided according to location of lesion (crural vessels, femoral or femoropopliteal vessels, and mixed lesions, which are all infrainguinal)

stenosis in the treated segment; and (3) patency of the segment without intervention. Definitions 1 and 2 are taken together because of the clinical irrelevance of such a difference. Primary and primary assisted patency were about $50 \%$ after 1 year (Tables 5-7).

\section{Limb Salvage}

The most common definition of limb salvage was salvation of the leg not further specified. Two studies $[18,26]$ made the definition more explicit, to state that limb salvage was

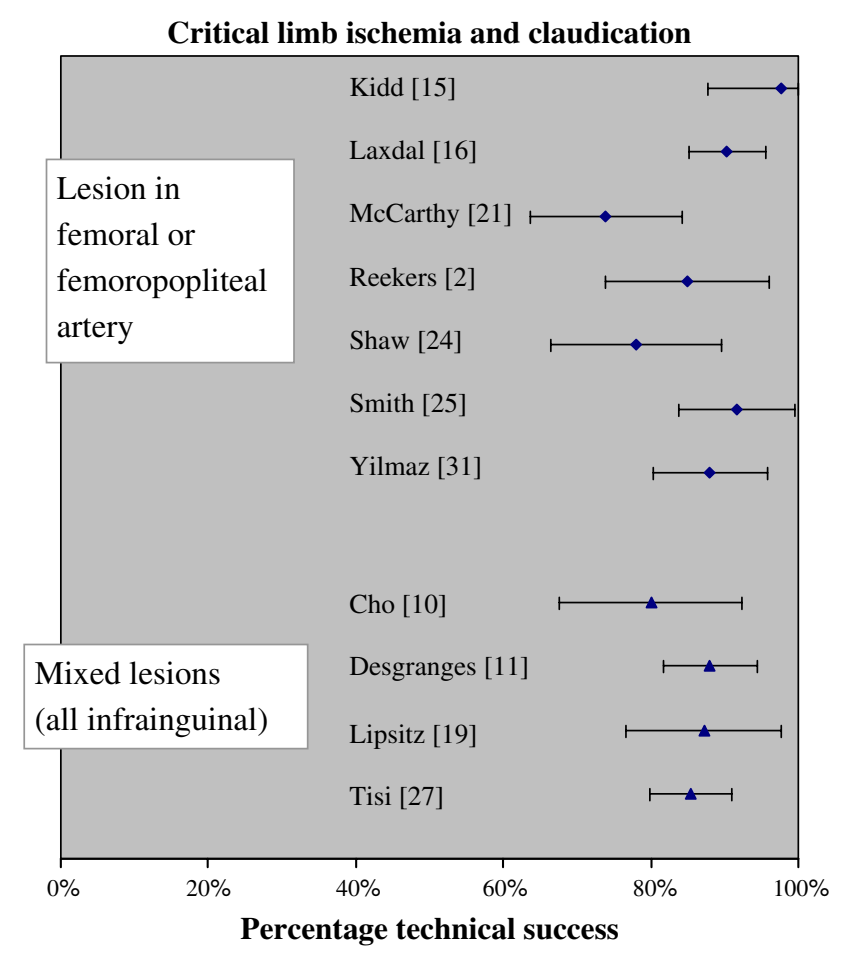

Fig. 3 Meta-analysis of technical success accompanied by 95\% confidence interval of all studies reporting patients with critical limb ischemia and claudication (mixed), subdivided according to location of lesion (femoral or femoropopliteal vessels and mixed lesions, which are all infrainguinal)

maintained even when a minor amputation was needed. Most limb salvage rates are about $80 \%$ to $90 \%$, one study [26] reporting about patients with CLI and mixed lesions report a limb salvage rate of $66 \%$ after 1 year (Tables 5-7).

\section{Survival}

Survival was given for different time periods and different patient selections. Studies reporting only on patients with CLI showed lower survival rates compared with studies 


\section{Claudication}

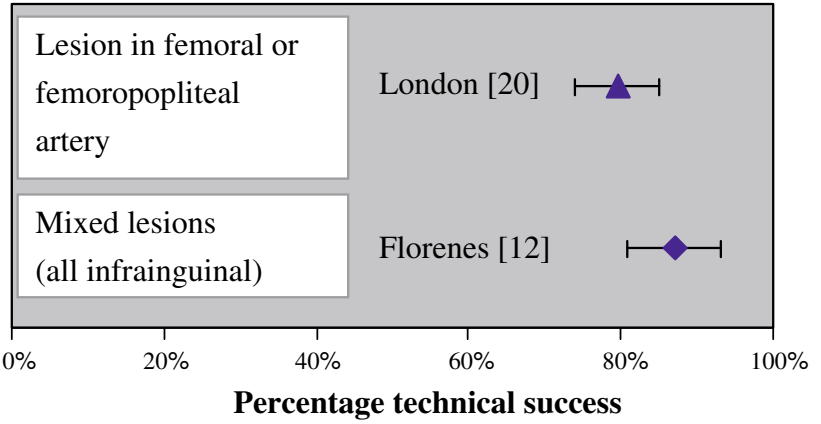

Fig. 4 Percentage technical success accompanied by $95 \%$ confidence interval of two studies reporting patients with intermittent claudication. London et al. [20] report about patients with lesions in the femoral or femoropopliteal vessels; Florenes et al. [12], about patients with mixed lesions (all infrainguinal)

reporting patients with different stages of disease. Patients with CLI and a crural lesion demonstrate a survival after 1 year of from $65 \%-78 \%$, in contrast to a survival of between $86 \%$ and $100 \%$ after 1 year for patients with mixed disease and a femoral lesion.

\section{Complications}

Most frequently reported complications include hematoma of the groin, perforation of the artery, and distal embolism. Also, pseudoaneurysms of the femoral artery, retroperitoneal hematomas, and myocardial infarctions were reported. Complication rates for all studies were mostly between $8 \%$ and $17 \%$. One study [22], reporting about patients with CLI and a femoral lesion, reports $2 \%$ complications; another study [2], reporting about patients with mixed disease and femoral lesions, reports a complication rate of $20 \%$.

\section{Discussion}

This systematic review shows that SA can be a useful option in the treatment of patients with severe critical leg ischemia. After 1 year, limb salvage rates are between $80 \%$ and $90 \%$, irrespective of whether the occlusion is in the femoral or femoropopliteal artery or in the crural arteries.

Although there were no comparative studies, SA seems to have lower patency rates than surgery. The primary patency of lower limb surgical bypass is high, $83 \%$ for an above-knee femoropopliteal bypass with a saphenous vein graft, $78 \%$ for a PTFE graft [32] and $82 \%$ even for a popliteal-to-distal vein bypass after 1 year [33]. The primary patency rates after 1 year for SA were about $50 \%$. The lower patency rates must be balanced against the advantage that SA is a minimally invasive technique that requires only local anesthesia, which are great advantages with respect to surgical revascularization procedures. Individual patient characteristics, like age and pattern of disease, will determine the choice between a percutaneous and a surgical approach.

The benefit of SA for patients with intermittent claudication is more indistinct. Two studies [12, 20], including only claudicants, reported a clinical success of $58 \%$, a primary patency of $56 \%$ after 1 year, and a primary assisted patency of $56 \%$ after 3 years. There are several treatment options for patients with intermittent

Table 5 Outcomes of studies reporting about patients with critical limb ischemia, subdivided according to location of lesion (crural, femoral or femoropopliteal vessels or mixed, which are all infrainguinal)

\begin{tabular}{|c|c|c|c|c|c|c|c|}
\hline Study & $\begin{array}{l}\text { Statistical } \\
\text { method }\end{array}$ & $\begin{array}{l}\text { Clinical } \\
\text { success (mo) }\end{array}$ & Complications & $\begin{array}{l}\text { Primary } \\
\text { patency (mo) }\end{array}$ & $\begin{array}{l}\text { Primary assisted } \\
\text { patency }(\mathrm{mo})\end{array}$ & $\begin{array}{l}\text { Limb } \\
\text { salvage (mo) }\end{array}$ & $\begin{array}{l}\text { Survival } \\
(\mathrm{mo})\end{array}$ \\
\hline \multicolumn{8}{|l|}{ Lesion (mostly) in crural vessels } \\
\hline Ingle [14] & KMA & - & $9 / 70(13 \%)$ & - & - & $94 \%(12)$ & - \\
\hline Nydahl [23] & KMA & $56 \%(12)$ & $3 / 28(11 \%)$ & $53 \%(12)^{\mathrm{a}}$ & - & $85 \%(12)$ & - \\
\hline Vraux \& Hammer [29] & KMA & $68 \%(12)$ & $5 / 40(13 \%)$ & $56 \%(12)^{\mathrm{b}}$ & - & $81 \%(12)$ & $78 \%(12)$ \\
\hline Vraux \& Bertoncello [30] & KMA & $63 \%(12)$ & $7 / 50(14 \%)$ & $46 \%(12)^{\mathrm{b}}$ & - & $87 \%(12)$ & $65 \%(12)$ \\
\hline \multicolumn{8}{|c|}{ Lesion (mostly) in femoral or femoropopliteal artery } \\
\hline Hynes [13] & LTA & - & $6 / 74(8 \%)$ & - & - & - & - \\
\hline Myers [22] & KMA & - & $2 / 82(2 \%)$ & $74 \%(3)^{\mathrm{a}}$ & $87 \%$ (3) & - & - \\
\hline Treiman [28] & KMA & - & $4 / 29(14 \%)$ & $64 \%(24)^{\mathrm{b}}$ & - & $80 \%(24)$ & $50 \%(24)$ \\
\hline \multicolumn{8}{|l|}{ Mixed lesions (all infrainguinal) } \\
\hline Lazaris \& Tsiamis [17] & KMA & $69 \%(24)$ & $14 / 112(13 \%)$ & - & - & $88 \%(12)$ & - \\
\hline Lazaris \& Salas [18] & KMA & - & - & $50 \%(12)^{\mathrm{b}}$ & - & $92 \%(12)$ & $87 \%(12)$ \\
\hline Spinosa $[26]$ & KMA & - & $4 / 40(10 \%)$ & - & - & $66 \%(12)$ & $71 \%(12)$ \\
\hline
\end{tabular}

Note: KMA, Kaplan-Meier analysis; LTA, life-table analysis

${ }^{a}$ Definition of patency is absence of occlusion and absence of $>50 \%$ or $>30 \%$ stenosis in treated segment

${ }^{b}$ Definition of patency is patency of segment without intervention 
Table 6 Outcomes of studies reporting about patients with critical limb ischemia or intermittent claudication (mixed), subdivided according to location of lesion (femoral or femoropopliteal artery or mixed lesions, which are all infrainguinal)

\begin{tabular}{|c|c|c|c|c|c|c|c|}
\hline Study & $\begin{array}{l}\text { Statistical } \\
\text { method }\end{array}$ & $\begin{array}{l}\text { Clinical success } \\
(\mathrm{mo})\end{array}$ & Complications & $\begin{array}{l}\text { Primary } \\
\text { patency (mo) }\end{array}$ & $\begin{array}{l}\text { Primary assisted } \\
\text { patency (mo) }\end{array}$ & $\begin{array}{l}\text { Limb } \\
\text { salvage (mo) }\end{array}$ & $\begin{array}{l}\text { Survival } \\
(\mathrm{mo})\end{array}$ \\
\hline \multicolumn{8}{|c|}{ Lesion (mostly) in femoral or femoro-popliteal artery } \\
\hline Kidd [15] & LTA & - & - & $52 \%(12)^{\mathrm{a}}$ & - & $100 \%(12)$ & $98 \%(12)$ \\
\hline Laxdal [16] & KMA & - & $9 / 124(7 \%)$ & - & $37 \%(12)$ & $90 \%(7)$ & - \\
\hline McCarthy [21] & KMA & $60 \%(8)$ & $11 / 69(16 \%)$ & $51 \%(6)^{\mathrm{a}}$ & - & $88 \%(8)$ & $86 \%(6)$ \\
\hline Reekers [2] & LTA & $50 \%(12)$ & $8 / 40(20 \%)$ & $59 \%(12)^{\mathrm{a}}$ & - & - & - \\
\hline Shaw [24] & KMA & $59 \%(6)$ & $5 / 50(10 \%)$ & $57 \%(6)^{\mathrm{a}}$ & - & - & $89 \%(6)$ \\
\hline Smith [25] & KMA & - & $7 / 47(15 \%)$ & $53 \%(12)^{\mathrm{a}}$ & - & - & - \\
\hline Yilmaz [31] & KMA & - & $10 / 67(15 \%)$ & $22 \%(12)^{\mathrm{a}}$ & $57 \%(12)$ & - & $100 \%(12)$ \\
\hline \multicolumn{8}{|c|}{ Mixed lesions (all infrainguinal) } \\
\hline Cho $[10]$ & KMA & - & $4 / 40(10 \%)$ & $44 \%(12)^{\mathrm{b}}$ & - & - & - \\
\hline Desgranges [11] & LTA & - & $17 / 100(17 \%)$ & $61 \%(24)^{\mathrm{a}}$ & $69 \%(24)$ & $78 \%(24)$ & $85 \%(24)$ \\
\hline Lipsitz [19] & LTA & $68 \%(12)$ & $3 / 39(8 \%)$ & $64 \%(12)^{\mathrm{b}}$ & - & $92 \%(12)$ & - \\
\hline Tisi [27] & LTA & - & $26 / 158(16 \%)$ & $45 \%(1)^{\mathrm{a}}$ & - & - & - \\
\hline
\end{tabular}

Note: KMA, Kaplan-Meier analysis; LTA, life-table analysis

${ }^{a}$ Definition of patency is patency of segment without intervention

b Definition of patency is absence of occlusion and absence of $>50 \%$ or $>30 \%$ stenosis in treated segment

Table 7 Outcomes of studies reporting about patients with intermittent claudication, subdivided according to location of lesion (femoral or femoropopliteal artery or mixed lesions, which are all infrainguinal)

\begin{tabular}{|c|c|c|c|c|c|c|c|}
\hline Study & $\begin{array}{l}\text { Statistical } \\
\text { method }\end{array}$ & $\begin{array}{l}\text { Clinical } \\
\text { success } \\
(\mathrm{mo})\end{array}$ & Complications & $\begin{array}{l}\text { Primary } \\
\text { patency } \\
(\mathrm{mo})\end{array}$ & $\begin{array}{l}\text { Primary } \\
\text { assisted } \\
\text { patency (mo) }\end{array}$ & $\begin{array}{l}\text { Limb } \\
\text { salvage } \\
\text { (mo) }\end{array}$ & $\begin{array}{l}\text { Survival } \\
\text { (mo) }\end{array}$ \\
\hline \multicolumn{8}{|c|}{ Lesion (mostly) in femoral or femoro-popliteal artery } \\
\hline London [20] & KMA & $58 \%(12)$ & $15 / 200(8 \%)$ & $56 \%(12)^{\mathrm{a}}$ & - & - & - \\
\hline \multicolumn{8}{|c|}{ Mixed lesions (all infrainguinal) } \\
\hline Florenes [12] & KMA & - & $20 / 116(17 \%)$ & - & $56 \%(36)$ & - & - \\
\hline
\end{tabular}

Note: KMA, Kaplan-Meier analysis

${ }^{a}$ Definition of patency is absence of occlusion and absence of $>50 \%$ or $>30 \%$ stenosis in treated segment

claudication, ranging from conservative to invasive. SA could be useful in claudicants, but since patency rates are low, this option should be offered with reserve.

The technical success rates of SA were about $80 \%$, with higher success rates in the femoral or femoropopliteal arteries compared with the crural arteries. Although most studies do not report the experience of the interventional radiologist, which is an important factor determining outcome of SA, these good technical success rates could indicate that the procedure is not only reserved for experts. Second, the included studies are originating from many different centers, indicating that many interventionalists are currently practicing SA, indicating that this technique is probably not so difficult to learn.

Approximately $15 \%$ of the procedures is complicated by a puncture-site hematoma, vessel perforation, or distal embolus. This is comparable to the incidence of complications after PTA (11\%) [34]. However, the reported complication rates ranged between $2 \%$ and $20 \%$. It is likely that various definitions and different registration systems for complications were used, which makes these numbers hard to interpret. It can be argued that complications are related to the site of the lesion. The risk of a groin hematoma does not depend on the site of the lesion, however, crural vessels are more fragile and might therefore be at greater risk of perforation. We observed that studies reporting solely about femoral or femoropopliteal lesions reported fewer cases of perforation. It should be noted that major complications, like myocardial infarction, renal failure, and in-hospital mortality, are probably underreported. In general, such complications should be registered as well, to fully appreciate the effect of interventions in this fragile group of patients.

This systematic overview of best evidence has several limitations. First, the only available publications for this systematic review were case series (observational studies). 
An additional limitation is selection bias, which causes overestimation of treatment effects. Many studies did not provide data about the entire cohort of patients, including those who underwent surgery as the initial procedure or conservative treatment in the case of claudication. Moreover, we must assume publication bias to be likely, another cause of overestimation of the results. To determine the exact value of SA, a randomized controlled trial in which SA is compared to surgery would be ideal. From earlier randomized trials in patients with critical limb ischemia (BASIL trial [35]), only a small number seems to be eligible for randomization due to local anatomy. However, experience with SA is still evolving, and at our hospital bypass surgery for critical limb ischemia has been reduced by more than $50 \%$ over the past decade, indicating that a significant number of patients can be treated by SA. A major obstacle for randomized trials is the preference of patients as well as of treating physicians for minimally invasive techniques as first-line treatment, knowing that surgery is still in reserve [36].

We noticed a wide variation in reporting of patient characteristics and in definitions of outcome and complications of subintimal angioplasty. First, a whole scale of outcome measurements and definitions of outcomes was used. We have tried to sort out all these different outcomes. Second, different statistical methods were used to determine outcome. Most authors did Kaplan-Meier analysis, whereas others used life-table analysis. Some authors reported patency and limb salvage rates for the total group of treated patients; others, only for the technically successful cases. Also, data on follow-up were reported insufficiently; the number of patients lost-to-follow-up and the reasons for that remained unclear most of the time. These shortcomings in methodology and reporting make it difficult to compare results, and made us decide not to perform any meta-analysis. Therefore, we like to stress the importance of using standards for reporting results of treatment for peripheral arterial disease and, especially, for lower-extremity arterial endovascular procedures, to facilitate future meta-analyses [37, 38].

In conclusion, this systematic review shows that, especially in the treatment of critical limb ischemia, SA can play an important role. Despite the moderate long-term patency rates of the revascularized segments, SA may serve as a "temporary bypass" to provide wound healing and limb salvage. Further studies of higher methodological quality should include and analyze entire cohorts of patients admitted for CLI, instead of selected series, to better appreciate the value of SA in relation to bypass surgery.

Open Access This article is distributed under the terms of the Creative Commons Attribution Noncommercial License which permits any noncommercial use, distribution, and reproduction in any medium, provided the original author(s) and source are credited.

\section{References}

1. Bolia A, Miles KA, Brennan J et al (1990) Percutaneous transluminal angioplasty of occlusions of the femoral and popliteal arteries by subintimal dissection. CardioVasc Interv Radiol 13(6):357-363

2. Reekers JA, Kromhout JG, Jacobs MJ (1994) Percutaneous intentional extraluminal recanalisation of the femoropopliteal artery. Eur J Vasc Surg 8(6):723-728

3. Bolia A, Sayers RD, Thompson MM et al (1994) Subintimal and intraluminal recanalisation of occluded crural arteries by percutaneous balloon angioplasty. Eur J Vasc Surg 8(2):214-219

4. Sandford RM, Bown MJ, Sayers RD et al (2007) Is infrainguinal bypass grafting successful following failed angioplasty? Eur J Vasc Endovasc Surg 34(1):29-34

5. http://www.cochrane.nl/index.html. Accessed April 14, 2007

6. Stroup DF, Berlin JA, Morton SC et al (2000) Meta-analysis of observational studies in epidemiology (MOOSE) group: a proposal for reporting. JAMA 283(15):2008-2012

7. Bolia A, Bell PR (1995) Femoropopliteal and crural artery recanalisation using subintimal angioplasty. Semin Vasc Surg 8(3):253-264

8. Kocher M, Cerna M, Utikal P et al (2004) Subintimal recanalisation in femoropopliteal area-Short-term results. Ceska Radiol 58(3):142-146

9. Aleksynas N, Kaupas RS (2007) The influence of various factors on results of subintimal angioplasty of superficial femoral artery occlusions. Medicina (Kaunas) 43(6):43-50

10. Cho SK, Do YS, Shin SW et al (2006) Subintimal angioplasty in the treatment of chronic lower limb ischemia. Korean J Radiol 7(2):131-138

11. Desgranges P, Boufi M, Lapeyre M et al (2004) Subintimal angioplasty: feasible and durable. Eur J Vasc Endovasc Surg 28(2):138-141

12. Florenes T, Bay D, Sandbaek G et al (2004) Subintimal angioplasty in the treatment of patients with intermittent claudication: long term results. Eur J Vasc Endovasc Surg 28(6):645-650

13. Hynes N, Akhtar Y, Manning B et al (2004) Subintimal angioplasty as a primary modality in the management of critical limb ischemia: comparison to bypass grafting for aortoiliac and femoropopliteal occlusive disease. J Endovasc Ther 11(4):460-471

14. Ingle H, Nasim A, Bolia A et al (2002) Subintimal angioplasty of isolated infragenicular vessels in lower limb ischemia: long-term results. J Endovasc Ther 9(4):411-416

15. Kidd J, Bourke BM, Dunwoodie J et al (2006) The role of pre and postprocedural color duplex ultrasound for the treatment of lower limb ischemia by subintimal angioplasty. J Vasc Ultrasound 30(1):17-21

16. Laxdal E, Jenssen GL, Pedersen G et al (2003) Subintimal angioplasty as a treatment of femoropopliteal artery occlusions. Eur J Vasc Endovasc Surg 25(6):578-582

17. Lazaris AM, Tsiamis AC, Fishwick G et al (2004) Clinical outcome of primary infrainguinal subintimal angioplasty in diabetic patients with critical lower limb ischemia. J Endovasc Ther 11(4):447-453

18. Lazaris AM, Salas C, Tsiamis AC et al (2006) Factors affecting patency of subintimal infrainguinal angioplasty in patients with critical lower limb ischemia. Eur $\mathbf{J}$ Vasc Endovasc Surg 32(6):668-674

19. Lipsitz EC, Ohki T, Veith FJ et al (2003) Does subintimal angioplasty have a role in the treatment of severe lower extremity ischemia? J Vasc Surg 37(3):386-391

20. London NJ, Srinivasan R, Naylor AR et al (1994) Subintimal angioplasty of femoropopliteal artery occlusions: the long-term results. Eur J Vasc Surg 8(2):148-155 
21. McCarthy RJ, Neary W, Roobottom C et al (2000) Short-term results of femoropopliteal subintimal angioplasty. Br J Surg 87(10):1361-1365

22. Myers SI, Myers DJ, Ahmend A et al (2006) Preliminary results of subintimal angioplasty for limb salvage in lower extremities with severe chronic ischemia and limb-threatening ischemia. $\mathbf{J}$ Vasc Surg 44(6):1239-1246

23. Nydahl S, Hartshorne T, Bell PRF et al (1997) Subintimal angioplasty of infrapopliteal occlusions in critically ischaemic limbs. Eur J Vasc Endovasc Surg 14(3):212-216

24. Shaw MB, DeNunzio M, Hinwood D et al (2002) The results of subintimal angioplasty in a district general hospital. Eur J Vasc Endovasc Surg 24(6):524-527

25. Smith BM, Stechman M, Gibson M et al (2005) Subintimal angioplasty for superficial femoral artery occlusion: poor patency in critical ischaemia. Ann R Coll Surg Engl 87(5):361-365

26. Spinosa DJ, Leung DA, Matsumoto AH et al (2004) Percutaneous intentional extraluminal recanalization in patients with chronic critical limb ischemia. Radiology 232(2):499-507

27. Tisi PV, Mirnezami A, Baker S et al (2002) Role of subintimal angioplasty in the treatment of chronic lower limb ischaemia. Eur J Vasc Endovasc Surg 24(5):417-422

28. Treiman GS, Treiman R, Whiting J (2006) Results of percutaneous subintimal angioplasty using routine stenting. J Vasc Surg 43(3):513-519

29. Vraux H, Hammer F, Verhelst R et al (2000) Subintimal angioplasty of tibial vessel occlusions in the treatment of critical limb ischaemia: mid-term results. Eur $\mathrm{J}$ Vasc Endovasc Surg 20(5):441-446

30. Vraux H, Bertoncello N (2006) Subintimal angioplasty of tibial vessel occlusions in critical limb ischaemia: A good opportunity? Eur J Vasc Endovasc Surg 32(6):663-667
31. Yilmaz S, Sindel T, Yegin A et al (2003) Subintimal angioplasty of long superficial femoral artery occlusions. J Vasc Interv Radiol 14(8):997-1010

32. Klinkert P, Post PN, Breslau PJ et al (2004) Saphenous vein versus PTFE for above-knee femoropopliteal bypass. A review of literature. Eur J Vasc Endovasc Surg 27(4):357-362

33. Albers M, Romiti M, Brochado-Neto FC et al (2006) Metaanalysis of popliteal-to-distal vein bypass grafts for critical ischemia. J Vasc Surg 43(3):498-503

34. Pentecost MJ, Criqui MH, Dorros G et al Special Writing Group of the Councils on Cardiovascular Radiology, Arteriosclerosis, Cardio-Thoracic and Vascular Surgery, Clinical Cardiology, and Epidemiology and Prevention, American Heart Association (2003) Guidelines for peripheral percutaneous transluminal angioplasty of the abdominal aorta and lower extremity vessels. A statement for health professionals from a Special Writing Group of the Councils on Cardiovascular Radiology, Arteriosclerosis, Cardio-Thoracic and Vascular Surgery, Clinical Cardiology, and Epidemiology and Prevention, the American Heart Association. J Vasc Interv Radiol 14(9; Pt 2):S495-S515

35. Adam DJ, Beard JD, Cleveland T et al (2005) Bypass versus angioplasty in severe ischaemia of the leg (BASIL): multicentre, randomised controlled trial. Lancet 366(9501):1925-1934

36. Van der Zaag ES, Legemate DA, Prins MHet al (2004) Angioplasty or bypass for superficial femoral artery disease? A randomised controlled trial. Eur J Vasc Endovasc Surg 28(2):132-137

37. Rutherford RB, Baker JD, Ernst C et al (1997) Recommended standards for reports dealing with lower extremity ischemia: revised version. J Vasc Surg 26(3):517-538

38. Ahn SS, Rutherford RB, Becker GJ et al (1993) Reporting standards for lower extremity arterial endovascular standards. J Vasc Surg 17(6):1103-1107 